\title{
Toward the Blueprint of Campus-Based Ecosystems for Innovation
}

\author{
A. Georges L. Romme ${ }^{1}$ \\ ${ }^{1}$ School of Industrial Engineering, Eindhoven University of Technology, Eindhoven, Netherlands \\ Correspondence: A. Georges L. Romme, School of Industrial Engineering, Eindhoven University of Technology, \\ P.O. Box 513, 5600 MB Eindhoven, The Netherlands. Tel: 31-40-247-2170. E-mail: a.g.l.romme@tue.nl \\ Received: March 22, 2017 \\ Accepted: April 11, 2017 \\ Online Published: April 16, 2017 \\ doi:10.5539/emr.v6n1p84 \\ URL: http://doi.org/10.5539/emr.v6n1p84
}

\begin{abstract}
The "science park" model has long been showing signs of aging, with many science parks now facing budget cuts by local and regional governments. In this study, we dissect the blueprint of a highly successful campus-based ecosystem, the High Tech Campus Eindhoven (HTCE). As an innovation ecosystem, the HTCE provides its residents (a) access to shared resources and facilities, to facilitate research and product development, and (b) an innovation community that enhances knowledge sharing between people at the campus. The success of the HTCE arises from a deep and inclusive understanding of the conditions in which an ecosystem for research and development can thrive, and the commitment to carefully grow and sustain these conditions. These conditions include: low physical distances between the various buildings, offices and shared facilities; a dynamic portfolio of thematic workshops and meetings stimulate knowledge sharing and informal networking; careful management of the diversity and reputation of the campus; attracting and hosting "connectors" that have the capability to initiate and/or manage collaboration across a newly emerging value chain; and a high level of responsiveness to requests and feedback of residents.
\end{abstract}

Keywords: open innovation, knowledge sharing, ecosystem, innovation community, science park, product development

\section{Introduction}

The "science park" model has long been showing signs of aging (Cabral, 1998; Townsend, 2009). Moreover, many science parks are now in financial trouble, as a result of budget cuts by local and regional governments. In this study, we dissect the blueprint of a highly successful campus for research and product development, the High Tech Campus Eindhoven (HTCE). The HTCE is a campus-based ecosystem for developing hightech products and systems, located in the city of Eindhoven (Netherlands), which is completely privately owned and thus independent from any public funding. It is currently home to more than 140 companies and institutions, involving more than 10,000 product developers, researchers, entrepreneurs, and service providers.

The Financial Times, Fortune, Forbes and many others have praised the HTCE as one of the best locations in the world for hightech venture development and startup activity (Akhtar, 2012; Alison, 2014; Egusa \& Cohen, 2015; Kalliagkopoulos, 2014; McReynolds, 2014; Pentland, 2013). Moreover, the OECD observed that the HTCE is the most inventive "square kilometer" on the planet, in terms of patent density (Egusa \& Cohen, 2015; Pentland, 2013). Henry Chesbrough, a leading scholar in the field of "open innovation", has followed the HTCE since its inception: "I have visited the campus numerous times, and can attest to the energy, vitality and diversity of the more than 10,000 scientists and engineers located there. HTCE is truly an exemplary example of open innovation, with the wonderful physical layout, the many different companies and technologies housed there, and the savvy to help newcomers plug into this vibrant open innovation ecosystem".

In this article, the key characteristics of HTCE's capability as an innovation ecosystem are depicted and illustrated. First, HTCE's history and current offerings are outlined. Subsequently, I explore what has been fueling its success.

\section{History}

Philips was the original driving force behind the establishment of HTCE. Until the late 1990s, Philips operated all its Research and Development (R\&D) activities in its famous NatLab, the breeding ground for many successful Philips products as well as a large number of hightech startups, some of which became a leading Original Equipment Manufacturer (OEM) themselves - such as ASML and NXP. To reinforce the interaction between researchers and product developers with different technical backgrounds, Philips decided to open up its main 
NatLab facility to other companies in 2003, renaming it the High Tech Campus Eindhoven. The result was a substantial growth in the number of high-tech companies and other residents-both large and small. In 2012 the HTCE was sold by Philips to Ramphastos Investments, a consortium of investors. Philips remained on the Campus as a tenant, but its status changed from owner/manager to resident.

Since 2012, the HTCE has continued to attract new companies and research institutes engaging in advanced R\&D - in the area of high tech systems, nanotechnology, smart pharma, embedded systems, life sciences, and security and encryption. HTCE researchers submit, on average, 4 patents a day; this is more than 50 percent of all patent applications in the Netherlands (Van Agtmael \& Bakker, 2016). Van Agtmael and Bakker (2016, p. 82) thus observed that the HTCE "has enjoyed astonishing success so far. More than one hundred organizations-including global players Intel, IBM, ABB, ASML and Philips-have now located at least part of their research activities to the campus, and more than 8,000 R\&D engineers from sixty countries are employed there".

\section{What the HTCE Offers}

One key goal of the HTCE is to foster cooperation between companies in hightech systems, nanotechnology, smart pharma, life sciences, embedded systems, encryption, and related areas. The high density of researchers and entrepreneurs at HTCE makes it into a so-called innovation district (Katz \& Wagner, 2014), but I will use the term $R \& D$ ecosystem here. The high density and proximity of people at HTCE promotes trust, which in turn encourages a faster exchange of ideas when two or more persons (from different companies) meet to talk about mutual interests.

The HTCE provides basic services such as office facilities and parking space. But HTCE's key offering in the area of high tech systems, nanotechnology, smart pharma, embedded systems, life sciences, and security and encryption is to facilitate $R \& D$ and product development by

- providing access to innovation services - in the area of, for example, materials analysis, high-end laser job shop prototyping, production facilities for electronics and mechanical products, product certification, electronic instrumentation and photonic equipment; and

- creating and sustaining an innovation community that enhances informal networking and knowledge sharing between (R\&D engineers of) the companies and institutes at the campus (Van der Borgh, Cloodt, \& Romme, 2012).

This combined offering appeals to hightech companies of all sizes. It attracts large corporates such as ABB, ASML, IBM, Intel, and NXP, but also many small companies. The med-tech start up G-Therapeutics, for example, recently acquired $€ 36$ million in funding and made a conscious choice to locate its product development activities on the HTCE, says the CEO of this Swiss-Dutch start up: "The High Tech Campus is a great place to be for international tech talent. It's great to have such a large community with various skills. The physical proximity of big corporates is also a plus. When needed I can easily connect to people there".

Another example is Life Sense, a fast-growing startup in the area of sensor technology that develops protective and re-usable underwear. For Valer Pop, the CEO of Life Sense, the HTCE is not only the birth place of his company but also fuels its growth: "For me and my company, the High Tech Campus Eindhoven is the number one location in the world. Life Sense is based here, but almost all our revenue is generated outside the Netherlands. And having the HTCE on my business card greatly helps in closing deals in the US, Japan or anywhere elsewhere in the world. It's like an endorsement: people simply trust me when I say that Life Sense is based at this campus, that has a global reputation ever since Philips created many of its successful products here. My ambition, thus, is to create a new Philips at the HTCE".

\section{Distinctiveness}

HTCE's value proposition, as depicted above, may in itself not be unique. Other location-based ecosystems, such as many science parks (Townsend, 2009), are offering a similar proposition. However, the HTCE appears to be distinctive in how it systematically practices and implements its key offering, drawing on a deep understanding of what makes it tick as an R\&D ecosystem. This blueprint of the HTCE can be summarized in the following five conditions and mechanisms (cf., Cloodt et al., 2016). These conditions and mechanisms also serve to (practically) connect the highly fragmented literature on regional collaboration, innovation hotspots, knowledge sharing, ecosystem development, value chains and related topics (e.g., Boschma, 2005; Chesbrough, 2012; Gilsing, Van Burg, \& Romme, 2010; Iansiti \& Levien, 2004; Katz \& Wagner, 2014; Leten et al., 2013; Nijssen \& van der Borgh, 2017; Romme, 1997). 


\subsection{Engineers Thrive on Direct Interaction and Collaboration}

The physical distances between buildings and offices at the HTCE are minimal, which provides for easy access to technological facilities as well as other people at the campus. At the heart of the campus is the "The Strip", hosting a variety of facilities such as restaurants, grand cafés, conference rooms, a food market, and a wellness/fitness center. This central area of the HTCE has been deliberately designed to connect people and stimulate knowledge sharing and collaboration. A key implication of this design is that all other buildings at the campus do not have any canteens or restaurants, which provides an extra motivation for many people to frequently walk to The Strip area.

Elsewhere on the campus, a large variety of outdoor sports facilities is available, including tennis courts, soccer pitches, volleyball and basketball courts, and running and workout circuits. There is also a (former) farm house at the HTCE, for a variety of social events. Overall, the short distances at the HTCE appear to facilitate direct interaction and collaboration between people.

\subsection{Informal Networks and Knowledge Sharing}

Short distances to others at the campus are, obviously, not enough to make people interact with each other. A key assumption therefore is that "networks cannot be copied nor can they be easily established", according to Bert-Jan Woertman, member of HTCE's management team (Katz \& Wagner, 2014, p. 13). The HTCE therefore deliberately hosts a large number of events, to facilitate informal networking and knowledge sharing. This is done by a variety of thematic workshops and seminars, meet and match events, quiz nights, open lectures, drinks and demo sessions, sports and recreational events, and many other informal events.

A large number of campus events are initiated and organized by members of the HTCE community, and others are organized by the campus management team. As a result, the HTCE hosts about 500 events every year. A substantial number of events focus on the social dimension - such as sport tournaments, quiz nights, and other recreational events. But most events are set up as network meetings or thematic sessions, to connect people with a shared interest-for example in a particular emerging technology.

\subsection{Managing the Ecosystem's Diversity and Reputation}

The HTCE manages the diversity of its ecosystem in two complementary ways. For one, it grows and sustains the diversity of the population of residents, within the scope of HTCE's profile. Second, HTCE's management team deliberately seeks to build and maintain its reputation, by selecting new residents that fit and reinforce its profile as well as motivating residents that do not (or no longer) contribute to its ecosystem to leave.

This balancing act, between growing the ecosystem's diversity and sustaining its profile and reputation, implies the HTCE must deliberately facilitate the exit of residents that no longer fit its value proposition. The case of Liquavista, a spinoff from Philips that was later acquired by Samsung and Amazon, illustrates why it is important to enable an exit. Liquavista initially decided to locate on the HTCE, but at some point discovered it no longer needed the state-of-the-art clean rooms available at the campus, and therefore decided to move elsewhere (Van der Borgh et al., 2012). Managing the diversity and reputation of the campus is key to its success, says Frans Schmetz (managing director of HTCE): "Managing the mix of residents at the campus is an important task for me and my management team, one that helps maintain the unique profile and global reputation of this campus. We're $100 \%$ privately owned, which creates clarity and speed, but also implies we need to be profitable in order to invest in future campus developments. We thus have to maintain a very delicate balance. On the one hand, we have square meters to be rented by companies and also have quite some unused space to be further developed. On the other hand, it is super important that we attract the right companies to the campus. Therefore, we carefully assess each applicant in terms of the fit with our profile and what this newcomer would contribute to the existing facilities, infrastructure, or community at the HTCE. We've especially been very selective with regard to firms in the periphery of hightech R\&D, such as many service providers".

\subsection{Connectors That Initiate and Manage Collaboration}

Creating value from complex R\&D networks of enterprises and other organizations cannot be done without connectors. A connector has a key role in bringing together organizations across a particular, newly emerging, value chain. Over the years, the HTCE has attracted several programs and organizations that provide capabilities for initiating and managing collaboration between these residents. Examples of these connectors are Solliance, Holst Centre, EIT Digital, ARTEMIS, ITEA, and High Tech NL. For instance, Solliance is a joint venture of several research institutes and universities that have combined forces in developing the next generation of solar cells. At the HTCE, the academic and industrial partners of Solliance work together in testing and producing thin-film PV modules. 
An important connector at the HTCE is the Holst Centre that, with more than 30 industrial partners and around 200 employees, develops generic technologies in the area of wireless autonomous sensor solutions and flexible electronics. A key feature of the Holst Centre is its partnership model with industry and academia, based on shared roadmaps and programs. One of many spinoffs created by the Holst Centre is Life Sense, the fast-growing startup in the area of sensor technology mentioned earlier.

The HTCE has also set up HighTech XL, an incubation and acceleration program that has grown into the leading hub for hightech startups in Europe. HighTech XL supports hardware startup founders, from idea to prototype to scale-up, by connecting them to a top-tier community of entrepreneurs, corporates, and investors. The HTCE ecosystem also benefits from the presence of connectors elsewhere in the region, such as Brainport Industries, Sioux, Mikrocentrum, and Eindhoven University of Technology. For example, Sioux has been successfully orchestrating several new value chains in the area of high-end equipment for precision engineering (Van Agtmael \& Bakker, 2016).

\subsection{Responsiveness to What Residents Need}

Last but not least, an important driver of HTCE's ecosystem is the responsiveness of its management team to highly different and dynamic needs. A hightech startup has, of course, rather different needs than the (R\&D unit of a) large corporate at the campus. The HTCE therefore continually monitors the level of satisfaction of its residents, via surveys and other tools.

More importantly, the HTCE management team serves the campus as an "excellent landlord that is very responsive, honest and straightforward in answering our questions and requests", says Guido Dierick, CEO of NXP Netherlands. This high level of responsiveness also pertains to unconventional requests. For instance, the HTCE effectively responded to a request from ABB that develops charging infrastructure for electrical vehicles (EV's) at the campus. Wil van Gils, VP Research \& Development at ABB: "In ABB's unit here at the campus, we're currently working on fast charging stations for electrical buses. This EV charging infrastructure operates on extremely high power levels, up to $450 \mathrm{~kW}$ or even higher. Last year, we needed a testing site where we could park a bus and connect it to the prototype of our charging station. This site needed to be as close as possible to our building on the campus, which is quite challenging given the substantial space required for moving and parking a bus. The campus management was very helpful in arranging a solution and providing the space that we needed".

\subsection{Overall Picture}

These five drivers of the HTCE ecosystem reinforce each other. For example, short distances between people reinforce opportunities for knowledge sharing. And the various network events as well as the capabilities of "connectors" help fuel the commercialization of breakthrough ideas and technologies (and their value chains) emerging from the HTCE ecosystem. Engaging in only a few of these activities would make the HTCE much less successful in implementing its key offering. The success of this ecosystem arises from a deep and inclusive understanding of the conditions for a vibrant R\&D ecosystem, and the commitment to carefully grow and sustain these conditions. Guido Dierick, CEO of NXP Netherlands, thus believes the HTCE provides a very attractive location for NXP: "This campus is a perfect location for the hightech talents we are looking for. Its global reputation as well as the presence of many other tech companies makes it highly attractive for people to come and work for NXP. In recruiting new talent, we explicitly use HTCE's reputation as the "smartest square kilometer on earth". The HTCE provides a very pleasant, green and vibrant location for our staff, at the center of the highly innovative Eindhoven-Brainport region. At NXP, we especially appreciate the excellent facilities, including the conference center, gym, supermarket, many restaurants and other services - all available within walking distance.

The overall picture of the HTCE as a leading location for hightech innovation is also supported by evidence that Inscope collects via the annual Erasmus Competition and Innovation Monitor. Based on this evidence, Henk Volberda concludes that companies at the HTCE have an exceptional focus on both performance and innovation. Moreover, he observes that the HTCE serves as a springboard for companies, including startups, to realize disruptive as well as incremental innovations: "We found that High Tech Campus Eindhoven is outperforming the others in all the innovation types. They show very high scores on radical innovation, incremental innovation, but also social innovation. (...) we're seeing evidence in our survey that they are leading with other types of innovation - co-create with partners, giving room for ideas for employees, getting rid of hierarchical pyramids" (High Tech Campus Eindhoven, 2015).

A similar observation is made by John Blankendaal, the managing director of Brainport Industries - a collaborative network of more than 90 suppliers in the value chains of ASML, DAF Trucks, NXP, Philips and several other OEMs: "The High Tech Campus Eindhoven plays an important role in creating the industries of the 
future. In close cooperation with other actors in the Brainport-Eindhoven ecosystem, the HTCE provides access and connections to many competences needed to realize the hightech ambitions of this region. It provides an innovation ecosystem from which new OEM's and value chains emerge, but also fuels the continuous renewal of existing value chains in the Brainport region and elsewhere".

These highly positive evaluations of the HTCE do not imply it is perfect. For example, Erik Vermeulen (2017) argued in a recent essay that the HTCE can further develop toward a more open and inclusive community, especially by embracing a more flexible and open workplace culture. These and other critical assessments will help the HTCE turn into "one of the most entrepreneurial square kilometers in the world, becoming even more attractive to companies, developers, creators and investors", says Vermeulen.

\section{Conclusion}

Overall, the HTCE provides an innovation ecosystem for companies in the area of hightech systems, nanotechnology, smart pharma, embedded systems, life sciences, and security and encryption. First, it provides access to shared resources and facilities, to facilitate R\&D and product development activities. Second, it is an innovation community that enhances knowledge sharing between people at the campus. In this respect, the HTCE draws on a deep understanding of how it creates value for its residents, by:

- minimizing the physical distances between the various buildings, offices and shared facilities, to enable direct interaction and collaboration;

- facilitating knowledge sharing and informal networking by offering a broad and dynamic portfolio of workshops, sessions and events;

- carefully managing the ecosystem's diversity and reputation, by gradually increasing the population of residents, within the scope of HTCE's profile, and being rather selective in accepting new companies on the campus;

- attracting and hosting "connectors" that have the capability to initiate and/or manage collaboration across a newly emerging value chain; and

- being highly responsive to questions, requests and feedback of residents.

Each of these conditions and mechanisms has been separately studied in the literature on, for example, regional collaboration (Katz \& Wagner, 2014), proximity (Boschma, 2005), science parks (Cabral, 1998), open innovation (Chesbrough, 2012), and ecosystem development (Clarysse et al., 2014; Leten et al., 2013). The HTCE case demonstrates how a vibrant innovation ecosystem can be designed and crafted by systematically integrating and applying this knowledge.

\section{Acknowledgements}

The author is grateful to members of the HTCE management team for comments on an earlier version of this article.

\section{References}

Akhtar, O. (2012). 7 best new global cities for startups. Fortune. Retrieved from http://fortune.com/2012/09/19/7-best-new-global-cities-for-startups/

Alison, C. (2014). Going Dutch: Why Europe's hottest Med Tech entrepreneurs are pitching up in The Netherlands. Forbes. $\quad$ Retrieved from http://www.forbes.com/sites/alisoncoleman/2014/07/16/going-dutch-why-europes-hottest-med-tech-entrepr eneurs-are-pitching-up-in-the-netherlands/\#1c792752759d

Boschma, R. A. (2005). Proximity and innovation: A critical assessment. Regional Studies, 39, 61-74. https://doi.org/10.1080/0034340052000320887

Cabral, R. (1998). Refining the Cabral-Dahab science park management paradigm. International Journal of Technology Management, 16, 813-818. https://doi.org/10.1504/IJTM.1998.002694

Chesbrough, H. W. (2012). Open innovation: Where we've been and where we're going. Research-Technology Management, 55, 20-27. https://doi.org/10.5437/08956308X5504085

Clarysse, B., Wright, M., Bruneel, J., \& Mahajan, A. (2014). Creating value in ecosystems: Crossing the chasms between knowledge and business ecosystems. Research Policy, 43, 1164-1176. https://doi.org/10.1016/j.respol.2014.04.014 
Cloodt, M., Hutama, R. P. F., Romme, A. G. L., \& Van der Borgh, M. (2016). Value creation within a campus-based ecosystem: Toward evidence-based guidelines. In Working paper. Eindhoven University of Technology.

Egusa, C., \& Cohen, S. (2015). The Netherlands: A Look at the world's high-tech startup capital. Tech Crunch. Retrieved from https:/techcrunch.com/2015/07/05/the-netherlands-a-look-at-the-worlds-high-tech-startup-capital/

Gilsing, V. A., van Burg, J. C., \& Romme, A. G. L. (2010). Policy principles for the creation and success of $\begin{array}{lllll}\text { corporate and } \quad \text { academic } & \text { 12-23. }\end{array}$ https://doi.org/10.1016/j.technovation.2009.07.004

High Tech Campus Eindhoven. (2015). HTCE is the global benchmark for Dutch innovation-Interview with Henk Volberda. Retrieved from http://blog.hightechcampus.com/build-your-business/htce-is-the-global-benchmark-for-dutch-innovation

Iansiti, M., \& Levien, R. (2004). The keystone advantage: What the new dynamics of business ecosystems mean for strategy, innovation and sustainability. Boston, MA: Harvard Business School Press.

Inscope. (2006-2016). Erasmus Competition and Innovation Monitor, annual reports 2006 to 2016. Retrieved from https://www.rsm.nl/inscope/innovation-monitor/

Kalliagkopoulos, N. (2014). 8+1 reasons Eindhoven is the dream location for a tech company. Venture Beat. $\begin{array}{ll}\text { Retrieved } & \text { from }\end{array}$ http:/venturebeat.com/2014/03/01/81-reasons-eindhoven-is-the-dream-location-for-a-tech-company/

Katz, B., \& Wagner, J. (2014). The rise of innovation districts: A new geography of innovation in America. Washington D.C.: Brookings Institution.

Leten, B., Vanhaverbeke, W., Roijakkers, N., Clerix, A., \& van Helleputte, J. (2013). IP models to orchestrate innovation ecosystems: IMEC, a public research institute in nano-electronics. California Management Review, 55, 51-64. https://doi.org/10.1525/cmr.2013.55.4.51

McReynolds, C. (2014). European cities and regions of the future 2014/15. Financial Times. Retrieved from http://www.fdiintelligence.com/Locations/Europe/European-Cities-and-Regions-of-the-Future-2014-15

Nijssen, E. J., \& Van der Borgh, M. (2017). Beyond the water cooler: Using socialization to understand use and impact of networking services on collaboration in a business incubator. R\&D Management, 47. https://doi.org/10.1111/radm.12261

Pentland, W. (2013). World's 15 most inventive cities. Forbes. Retrieved from http:/www.forbes.com/sites/williampentland/2013/07/09/worlds-15-most-inventive-cities

Romme, A. G. L. (1997). Organizational learning, circularity and double linking. Management Learning, 28, 149-160. https://doi.org/10.1177/1350507697282004

Townsend, A. (2009). Is there a future for science parks? Alternative scenarios for 2030 should inform policymaking. Science Progress. Retrieved from https://scienceprogress.org/2009/08/science-parks/

Van Agtmael, A., \& Bakker, F. (2016). The smartest places on earth: Why rustbelts are the emerging hotspots of global innovation. New York: Public Affairs.

Van der Borgh, M., Cloodt, M., \& Romme, A. G. L. (2012). Value creation by knowledge-based ecosystems: Evidence from a field study. $R \& D \quad$ Management, $42, \quad 150-169$. https://doi.org/10.1111/j.1467-9310.2011.00673.x

Vermeulen, E. P. M. (2017). Silicon valley: Beware of the "smartest square kilometer in the world"! Retrieved from

https:/medium.com/@erikpmvermeulen/silicon-valley-beware-of-the-smartest-square-kilometer-in-the-wor ld-cf287cd8f4fd\#.r5svzilyz

\section{Copyrights}

Copyright for this article is retained by the author(s), with first publication rights granted to the journal.

This is an open-access article distributed under the terms and conditions of the Creative Commons Attribution license (http://creativecommons.org/licenses/by/4.0/). 